\title{
Contar, falar e escrever números, mani- pular algoritmos: significa compreensão do Sistema de Numeração Decimal?
}

\author{
Celia Finck Brandt ${ }^{1}$ \\ Joseli Almeida Camargo ${ }^{1}$
}

\begin{abstract}
RESUMO
A pesquisa intervenção visa investigar a compreensão das crianças de $3^{\mathrm{a}} \mathrm{e}$ $4^{\text {a }}$ série, dos professores em serviço e das alunas do magistério, do valor posicional presente no Sistema de Numeração Decimal (S.N.D.). Tem por objetivos: identificar a compreensão dos sujeitos da estrutura de base dez; verificar as possibilidades para a construção da composição aditiva; avaliar as interferências dos rótulos verbais na construção da composição aditiva; identificar a compreensão da representação escrita correlacionada à compreensão do valor posicional; e interferir com proposições de situações de aprendizagem que permitam a compreensão significativa de todos os sujeitos envolvidos. A investigação compreendeu 14 testes propostos a crianças de $3^{\mathrm{a}}$ e $4^{\mathrm{a}}$ série de escolas públicas de Ponta Grossa, aplicados pelas pesquisadoras com acompanhamento dos professores regentes. As análises dos desempenhos apresentados foram efetuadas pelas pesquisadoras, professores regentes das turmas participantes, acadêmicos do Curso de Licenciatura em Matemática da Universidade Estadual de Ponta Grossa (UEPG) e alunas do Curso de Magistério $4^{\circ}$ ano. O procedimento metodológico de pesquisa compreendeu o método clínico piagetiano para o tratamento dos dados coletados. Alguns resultados já obtidos permitirão apontar como envolver diretamente o professor de sala de aula em pesquisa, não entendida aqui como pesquisa acadêmica, mas como possibilitadora de explicitação de representações próprias e dos outros.
\end{abstract}

Palavras-chave: sistema de numeração, valor posicional, formação de professores

${ }^{1}$ Professoras da Universidade Estadual de Ponta Grossa - Mestres em Educação

Olhar de professor, Ponta Grossa, 2 (2):161-179, nov. 1999. 
Representar quantidades constituiu e constitui uma das grandes necessidades do homem. Já não pertencemos mais a tribos ou civilizações cujo senso numérico só atingia o dois e qualquer quantidade superior significava pluralidade. Já não é possível também a utilização de formas de representação individualizadas ou personalizadas, visto que a globalização nos impele à utilização de um sistema de representação de quantidades padronizado e sistematizado. As informações que temos que acessar via jornal, televisão e outros meios de comunicação, bem como as informações que temos que processar para a leitura de mundo, estão carregadas de quantificação de todas as naturezas: temos que representar o tempo em dias, meses, anos, séculos, minutos, segundos; temos que ler a temperatura, ler o quanto pesamos ou pesam os objetos, contar o salário que recebemos, pagar as contas, os impostos, o lazer, a refeição, o aluguel, o ônibus; temos que interpretar as informações comunicadas numericamente.

A história registra a longa e árdua caminhada da humanidade para a invenção de um sistema de representação de quantidades. Nem todas vingaram, visto as ineficiências que só foram superadas pelo sistema de numeração, hoje conhecido como sistema de numeração decimal posicional indo-arábico, invenção que constitui a maior capacidade de síntese do homem . É ao mesmo tempo simples e sofísticado, razão pela qual sua com- preensão é fundamental. Sem heróis ou autores, superou os diversos sistemas criados, tornando-se quase universal. Os babilônicos também deram sua contribuição, pois o sistema de representação de tempo e de medidas de ângulos é sexagesimal, tal como o sistema por eles inventado.

Todas as civilizações lutaram, durante séculos, com a criação de um sistema de representação de quantidades. Os egípcios conseguiram superar o entrave de contar de um em um, mas não conseguiram superar a quantidade de símbolos necessários para a representação: para o 999 eles utilizavam 27 símbolos
@@@
V V V
I I I
@@@
V V V
a@@
V V V
I I I

Os romanos criaram um sistema que tornava difíceis as operações numéricas de adição, subtração, multiplicação e divisão. Não existem registros da utilização de algoritmos para a realização de operações, mas podemos ter uma idéia de quanto seria difícil tal tarefa. Vejamos uma adição:

\section{$24+39$ \\ XXIV \\ XXXIX}

Como o sistema não é aditivo, não podemos somar os dígitos da representação. Devemos considerar a lei que rege tal sistema: uma unidade à esquerda é subtraída e uma unidade à 
direita é adicionada. Logo, devemos considerar IV e IX como a soma de 4 e 9, que resulta em 13 .

\section{IV \\ $\mathrm{XXX} \quad \mathrm{IX}$ \\ XXXXX X111 Resultado: 63}

A soma direta dos símbolos da representação não forneceria o resultado correto da adição. Vejamos:

\section{XXIV}

\section{XXXIX}

\section{XXXXIIXV}

Se somados diretamente, dariam 67

O mesmo raciocínio seria válido para as outras operações. A verificação desse fato revela a não sofisticação desse sistema e, por essa razão, ele não se impôs como sistema de numeração. As fortes relações de poder e o amplo domínio político dos romanos tentaram impor tal sistema, que até hoje é utilizado para nomes de séculos, reis e mostradores de relógios. Até pouco tempo ele era amplamente ensinado nas escolas e constava do programa escolar de matemática proposto para as séries iniciais. As crianças deviam aprender a estrutura desse sistema e representar grandes quantidades utilizando os algarismos romanos. Levou tempo para que os professores começassem a questionar a importância de tal aprendizado, visto que encaminhar o processo de ensino para a construção de significados em relação ao nosso próprio sistema de numeração, não constitui uma tarefa fácil.

Outros sistemas foram inventados e necessitavam de desenhos, símbolos, posições e regras específicas que dificultavam as representações. Por essa razão o sistema de numeração indo - arábico se impôs como sistema de numeração, visto a utilização de apenas dez símbolos para a representação de quantidades.

Não é intenção deste texto relatar fatos históricos, o que nos preocupa de fato é que um sistema de representação de quantidades perde o seu significado e valor quando manipulado sem compreensão ou quando memorizado (como se cada número recebesse um nome específico). Isso implica em outras dificuldades quando da realização de operações matemáticas com utilização de algoritmos ou quando da extensão do campo numérico para valores não inteiros, cuja representação fracionária, decimal ou percentual também está baseada no mesmo sistema. Em decorrência, as dificuldades se estendem para o sistema de medidas de massa, área, volume, comprimento e para o sistema monetário, em que a representação segue o mesmo sistema de numeração, tornando-se confuso se não compreendido.

Esse é um fato concreto que observamos nas escolas. Os alunos, ao longo de sua escolaridade, vão apresentando muitas dificuldades com a manipulação do S.N.D e operações aritméticas que compreendem a manipulação de algoritmos. As primei- 
ras dificuldades aparecem quando da divisão de números naturais e se estendem para as operações com números decimais, cálculos de percentuais, representação de grandezas infinitamente grandes ou pequenas através da notação científica e conversões de unidades de medida.

Partimos da hipótese de que tais dificuldades só podem ser sanadas se investigarmos as suas origens e, neste caso específico, a compreensão das crianças do S.N.D utilizado para a representação de quantidades.

Por essa razão, propusemos uma pesquisa na UEPG, que busca investigar a compreensão do Valor Posicional presente no S.N.D. por alunos de $3^{\mathrm{a}}$ e $4^{\mathrm{a}}$ séries do ensino fundamental e também dos professores que atuam como regentes de classe.

Esta pesquisa justifica-se, portanto, pela exigência que se coloca da manipulação de um sistema de representação com compreensão e implica uma proposta que, de fato, leve as crianças à construção do S.N.D.

As crianças, nas escolas, manipulam os algoritmos ensinados; porém não sabem justificar por que fazem desta ou daquela forma. Elas absorvem informações e repetem procedimentos, posto que é somente esta a exigência por parte da escola. Sua aprovação para níveis mais avançados de escolaridade depende de repetição e memorização de técnicas específicas.

Poderíamos imaginar uma aula onde um professor, ao ensinar seus alunos, fizesse as seguintes afirmações:
$111+101=1100$ pois $1+1$ é zero e vai $1,1+1$ é zero e vai $1,1+1+1$ é 1 e vai $1, \log 01100$.

Ou então:

$121+122=1020$ pois $2+1$ é zero e vai $1,2+2+1$ é 2 e vai $1,1+1+1$ é zero e vai $1, \log 01020$.

Com o tempo não seria difícil para os alunos memorizarem alguns fatos básicos como $1+1$ é zero e vai 1 ou 1 $+1+1$ é 1 e vai 1 . Eles repetiriam com tranqüilidade para apresentarem soluções em testes e provas e garantir a promoção.

Para o leitor, essas afirmações poderiam parecer absurdas, porém, num sistema de numeração posicional de bases 2 e 3, respectivamente, as duas operações estariam corretas.

Não vemos diferença alguma no procedimento apresentado por um aluno que, ao somar $35+47$, faz: $5+$ $7=12$, fica 2 e vai 1 ; e $3+4+1$ é 8 . Ele sabe que é assim que se faz e é assim que tem que proceder, mas não sabe porque fica o 2 e vai 1 . Afirma que ali é o lugar do 2 , senão a conta dá errada.

Quando, nos graus mais elevados, as compreensões se colocam como contingências necessárias, cabe somente apontar culpados: "os alunos não querem nada com nada"; "os alunos não sabem multiplicar, dividir"; "os professores não souberam ensinar"; entre outros.

A presente investigação apresentou resultados significativos que me- 
recem ser relatados se, de fato, queremos enfrentar o fracasso escolar em matemática e promover a educação matemática necessária para o cidadão de hoje e de amanhã.

A pesquisa contou com a aplicação de 14 testes a crianças de 3 a e $4 a$ séries de duas escolas da rede estadual de ensino de Ponta Grossa. Os testes propostos foram elaborados e aplicados a outras crianças em outros lugares do mundo e são relatados nas obras de Kamii e Nunes (1). Os desempenhos das crianças em seis dos testes propostos já foram analisados e as análises e conclusões serão relatadas no presente texto.

Após cada teste, 24 crianças foram submetidas a entrevistas para argumentarem sobre as respostas dadas, caracterizando desta forma uma metodologia apoiada no método clínico piagetiano.

Uma amostra de 6 crianças, dentre as 24 , foi selecionada de forma aleatória (sorteio), para análise pelas pesquisadoras, pelos professores regentes de classe, por uma acadêmica do curso de Licenciatura em Matemática da UEPG e pela coordenadora de matemática do Núcleo Regional de Ensino de Ponta Grossa, da Secretaria de Estado da Educação (SEED).

Os encontros para análise do desempenho das crianças, relatados por escrito e nas transcrições das fitas gravadas, ocorreram quinzenalmente. A cada encontro, buscamos fundamentação teórica para interpretação dos desempenhos e conclusões.
Para a análise das respostas dadas pelas crianças recorremos à teoria de Piaget, que atribui significado essencial ao papel da ação na construção do conhecimento, aqui entendida como ação mental que inclui os processos de acomodação, assimilação e pode ser explicada pela abstração reflexionante. Tais processos são revelados frente aos desafios do ato cognoscitivo.

Para entendermos a construção das noções pelos sujeitos, precisamos considerar os papéis que a acomodação e a assimilação desempenham para darem conta de explicar o porquê do sujeito dar esta ou aquela resposta a um problema. Ao se deparar com uma situação problema, o sujeito se organiza para dar uma resposta. Segundo ROSSO (1999),

É aqui que se localiza a acomodação: a organização ou reorganização da forma de conhecer. [...] a acomodação manifesta-se através da progressiva exercitação de uma determinada forma de proceder diante dos desafios, tentando responder competentemente às mais diversas e mutantes situações representadas pelas novidades.[...] Quando o indivíduo realizar exitosamente a respectiva ação sobre o objeto, temos a assimilação do objeto (ROSSO et al, 1999, p.6).

Se ocorrer um desequilíbrio a favor da acomodação, estamos frente a uma 
assimilação parcial ou deformante dos objetos, que caracteriza a imitação.

No processo de formação matemática do aluno, há que se ter presente que diferentes formas de pensar significam diferentes formas de assimilação de um objeto matemático.

Segundo PIAGET,

[...] a abstração reflexionante (réfléchissante) [...] apoia-se sobre tais formas e sobre todas a atividades cognitivas do sujeito (esquemas ou coordenações de ações, operações, estruturas, etc) para delas retirar certos caracteres e utilizá-los para outras finalidades (novas adaptações, novos problemas, etc).[...] ela é reflexionante em dois sentidos complementares [...]:transpõe a um plano superior o que colhe no patamar precedente. [...] designaremos esta transferência [...] com o termo reflexionamento (réflechissement). [...] reconstruir sobre o novo plano $B$ o que foi colhido no plano de partida A, ou por em relação os elementos extraídos de A com os já situados em B. esta reorganização, [...], será designada por reflexão(réflexion). [...] nos níveis superiores quando a reflexão é obra do pensamento, [...] se torna, então uma reflexão sobre a reflexão [...] falaremos neste caso de abstração refletida (réflechie) ou de pensamento reflexivo. (1995, p.6)
Se pretendemos propor uma prática educativa para o trabalho com a matemática, eficaz e significativa, a partir da constatação de reais compreensões, devemos considerar os papéis da acomodação, assimilação e abstração, que apontem os significados atribuídos aos objetos matemáticos pelas crianças. Também considerar que existem níveis de desenvolvimento em relação aos processos de construção de conhecimentos, cujos estádios sucessivos são seqüenciais e resultam das possibilidades abertas pelo estágio precedente, condição necessária ao subseqüente.

Se a prática educativa não considerar tais elementos, consolidará uma realidade ilusória em que o professor aparentará estar ensinando, ao mesmo tempo em que promoverá uma camuflagem por parte das crianças, que fingirão estar aprendendo. Os comportamentos por imitação serão repetidos indefinidamente em sua vida escolar. Temos que distinguir a assimilação como origem generalizada dos instrumentos de aquisição da associação, concebida com simples relação de semelhança ou de contigüidade entre os objetos conhecidos ou a conhecer.

Apresentaremos agora os testes propostos e os desempenhos apresentados pelas crianças que constituem a amostra. Os resultados, conclusões e análises não podem ser generalizados, mas apontam indícios do que pode estar ocorrendo no ambiente da sala de aula, que passa desapercebido pelos professores. 


\section{OS TESTES}

TESTE 1 (KAMII, 1996, p. 87)

Descrição: Às crianças foram entregues dezesseis fichas. A elas foram solicitadas a contagem, a escrita do numeral representativo da quantidade e o desenho num papel. Em seguida, solicitou-se que as mesmas circulassem a quantidade de objetos que correspondia ao um, ao seis e ao dezesseis da representação. Uma outra quantidade de fichas também foi entregue, totalizando vinte e cinco, e a mesma tarefa deveria ser repetida (contagem, escrita, desenho e circulação da quantidade de objetos correspondente ao dois, ao cinco e ao vinte e cinco da representação)

Considerando os aspectos evidenciados na relação entre sujeito e objeto de conhecimento, na construção do conhecimento, passaremos agora a apresentar as análises relativas às respostas apresentadas pelas seis crianças da amostra, nos seis testes mencionados. Três categorias fundamentais foram identificadas:

a) as que já assimilaram o Valor Posicional presente no S.N.D;

b) as que se encontram num nível intermediário;

c) as que não assimilaram o Valor Posicional presente no S.N.D.

Em todos os níveis, porém, as crianças se organizaram para apresentar respostas às questões propostas nos testes e argumentaram segundo uma lógica que está construída de acordo com a sua compreensão do objeto matemático em questão.

FRA ( $4^{\mathrm{a}}$ série $)$

No teste 1, FRA associa cada dígito da representação com unidades e circula os objetos em unidades.

Seu desempenho pode ser visualizado no diagrama abaixo:

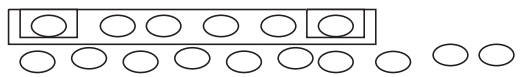

Isso significa que FRA ainda está construindo o seu sistema de unidades e, portanto, não está ainda preparada para enfrentar a construção de um sistema de base, que implica a construção de unidades de tamanhos diferentes, como é o caso do nosso Sistema de Numeração, onde vinte e dois significa um dígito dois representando vinte objetos e outro dígito dois, representando dois objetos. Isso porque, no nosso sistema de numeração, a posição dos algarismos na representação representa grupos de objetos e não objetos contados por unidades. Assim, para o vinte e cinco a criança circula dois objetos; e para o cinco, da representação, circula cinco objetos. Faz o mesmo com os dígitos do um e seis do numeral dezesseis utilizado para representar os dezesseis objetos. Ao desenhar os dezesseis, objetos, escreve os numerais $1,2,3,4, \ldots 16$ dentro de cada um dos desenhos.

O teste 1 permite identificar que FRA não construiu o conceito de cardinalidade, pois cada objeto da representação é para ela um objeto e o nome a ele atribuído refere-se àquele 
objeto, indicando portanto que a relação de inclusão hierárquica não é estabelecida. FRA encontra-se ainda em fase de construção do número, se considerarmos o que afirma Piaget, que a construção do número se dá pela síntese de duas relações: ordem e inclusão hierárquica, sendo que ordem significa contar todos e apenas uma vez (esta relação FRA estabelece) e inclusão hierárquica significa compreender que no dois estão incluídos o 1 e o dois; no três, o um, o dois e o três; e assim sucessivamente. É exatamente aí que se encontra a fragilidade de sua compreensão, significando que se encontra em estágio de construção do número. Como justificar, então, o fato de saber contar e nomear os objetos contados? Nesse sentido, um outro tipo de conhecimento também apontado por Piaget se manifesta, o conhecimento social. Os objetos contados são nomeados, como se cada um recebesse um nome a ser memorizado (o que significa um retrocesso, se considerarmos os fatos históricos) A criança tem que ultrapassar essa fase e entender como está organizado o S.N.D.

São esses objetos assimilados que permitem a FRA uma forma de se organizar (acomodação), para dar conta das outras questões que lhe são propostas.

Vamos agora apresentar uma outra criança e avaliar seus argumentos frente aos desempenhos apresentados.

DA ( $4^{\mathrm{a}}$ série), no teste 1 , circula corretamente dez fichas para o 1 do dezesseis, seis fichas para o seis e as dezesseis fichas para o dezesseis. Faz o mesmo para a quantidade de vinte e cinco fichas, circulando vinte fichas, cinco fichas e as vinte e cinco representando o numeral escrito. Ao argumentar porque faz dessa forma, diz:

DA-Eu circulei seis fichas para o seis do dezesseis porque ele representa seis unidades e o um que representa dez unidades ou uma dezena eu circulei dez fichas.

Cardinalidade e Valor Posicional são noções construídas por DA.

Outra criança foi identificada como se encontrando em um estágio intermediário de construção do objeto matemático.

MI (4a série) circula corretamente dez objetos para representar o dígito um do dezesseis e seis objetos para representar o seis do numeral utilizado. Porém, ao argumentar, diz ter circulado dez objetos porque eles valem dez dezenas. Ela acredita que os objetos, ao serem agrupados, passam a ser nomeados diferentemente, porém continuam sendo contados unitariamente. Isso significa que a representação começa a ganhar significado o que possibilita a circulação do número de objetos de forma correta de acordo com a posição do dígito na representação.

Eis o seu desempenho na tarefa:

\section{0}

As demais crianças como AL, FE e CLE também não apresentam compreensão do Valor Posicional presente no S.N.D. Uma dessas crianças, in- 
clusive, nem compreende o sistema de representação de quantidades. É o caso de FE que procede da seguinte forma às questões colocadas no teste 1 .

E-Você contou dezesseis fichas, desenhou e escreveu o numeral. Ai eu pedi para você circular quantas fichas valem o um do dezesseis e quantas fichas representam o seis do dezesseis. Como você fez?

FE-Circulei um para o um e seis para o seis.

E-Por que vale um?

FE-Porque algarismo, né.

E-Por que o algarismo vale um você circulou uma. E quantas para o seis? FE- $O$ seis.

E-O seis, o sexto. E o dezesseis?

FE- (A criança aponta a última)

$E-E$ as que não foram circuladas? $O$ que você me responde sobre elas?

FE-Porque não tinha o resto das bolinhas, se fosse o dois e o quatro junto com o dezesseis nós podemos circular.

E-Dois, quatro, junto com o dezesseis? Como assim, não estou entendendo. Explique de novo.

FE-Aqui tem o dezesseis e se tivesse o quatro e o sete...

E- Escreva para mim

FE- ( Ao lado do 16 FE escreve os dígitos 4 e 7, ficando 1647)

Dai depois do seis eu tenho que procurar o quatro (a criança conta e circula o quarto) e depois o sete (a criança conta e circula o sétimo).

E-Mas se você lesse esse número aqui, como você leria?

FE-Leria hum mil seiscentos e quarenta e sete..

E- E os demais que sobraram?

$F E-E u$ deixo. Eu faço outros numerais, pode ser 248, o dois no dois, quatro que é quarto lugar e oito.
No caso de FE, nem a escrita de números corresponde a um conhecimento social, como o identificado com FRA. Os nomes de números não representam cada um dos objetos de uma coleção, mas representam a posição ordinal do objeto na coleção. É esse o sentido atribuído por FE aos dígitos da representação.

TESTE 2 (KAMII, 1992, p. 39)

Descrição: As crianças deveriam efetuar a adição de 37 e 48 mentalmente e explicar como procederam para obter o resultado. Os desempenhos apresentados foram correlacionados com os desempenhos no teste 1 .

TESTE 4 ( KAMII, 1992, p.44)

Descrição: O entrevistador apresenta às crianças uma situação de subtração para ser resolvida com lápis e papel. 56 $-38$

As crianças deveriam explicar como procederam para obter o resultado. Em seguida, se a criança procedesse corretamente com a manipulação do algoritmo, o entrevistador lhe perguntava se, após o empréstimo, a quantidade ficou maior, menor ou igual. Os desempenhos apresentados também foram correlacionados com os apresentados no teste 1.

FRA, no teste 1, ao argumentar sobre o porquê de ter feito da forma indicada, responde tê-lo feito porque 
a professora pediu. Na manipulação do algoritmo, ela obtém êxito.

O procedimento de FRA, tanto no teste 1 como nos testes 2 e 4 , revela um comportamento por imitação, resultante de uma desequilibração favorável à acomodação. No ambiente escolar, porém, ela obtém êxito, visto que conta quantidades, representa-as e manipula algoritmos corretamente. Sua aprovação para graus mais elevados de escolaridade é um fato concreto, pois a sua compreensão não está sendo exigida. Ela desempenha bem por imitação e não sabe justificar em nenhum momento as suas ações. Tem que fazer assim porque é assim que se faz ou porque a professora diz que tem que fazer assim.

$\mathrm{Na}$ operação mental proposta para obter o valor da soma de $47 \mathrm{com}$ 38 e na operação de subtração para obter o resultado de 46 - 38 no papel, ela obtém os valores de 85 e 16 , respectivamente.

DA não apresenta desequilíbrio nem a favor da acomodação, nem a favor da assimilação. Sua compreensão do objeto de conhecimento, isto é, o Valor Posicional presente no S.N.D., pode ser explicada pela abstração reflexionante, pois o objeto de conhecimento é transferido para um outro patamar, reorganizado e colocado em relação com outros conhecimentos.
DA-Deu 85 porque eu somei oito mais sete igual a quinze e quatro mais três mais um deu oito.

E-De onde apareceu este 4 mais três mais um?

$D A$-É que antes era 37 mais 48 , somei primeiro as unidades e depois as dezenas.

E- Então quando deu quinze, como você fez com esse 15, você registrou ali embaixo do oito ou não?

DA-Não. Eu peguei o cinco que é unidade e a dezena que é um e pus na coluna das dezenas.

E- Na segunda operação que vocêfez, como obteve o resultado?

DA-Eu peguei o 6 que era unidade e não dava para eu tirar do seis o valor 8. Dai eu peguei do 5, emprestei um e ficou valendo 4 e o6 ficou valendo dezesseis. Então dezesseis menos 8 igual a 8 e 4, que antes era 5 menos 3 , 1.

E- E esse um que você emprestou vale um mesmo?

DA-Não. Vale dez.

A abstração reflexionante pode explicar, então, que se existe uma desequilibração a favor da assimilação, o objeto de conhecimento não pode ser transferido de um patamar A para outro patamar B, em que novas generalizações são necessárias e novas relações são exigidas, dependentes do conhecimento de um objeto matemático, no caso em questão, o Valor Posicional. Essa desequilibração a favor da assimilação não permite que a manipulação do algoritmo seja justificada. Vejamos como MI procedeu: 
Desempenho e argumentos utilizado no teste 2 e 4

E-Eu pedi para você me dizer quanto vale a soma de 38 mais 47. Quanto você achou?

MI- 85.

E-Agora me explique como você achou isso?

MI- Eu somei o 8 com o sete que dava quinze, e somei o 3 mais 4 e mais 1 que dava 8.

E-Por que você fez o 8 mais 7 que deu 15, você não deixou o 15 lá em baixo? O que você fez com o 1 do 15? MI- Eu ponhei do lado, eu somei o 8 mais 7 que dava 15, somei 4 mais 3 mais1.

E-Por que se diz mais 1 ?

MI- Porque não dá prá ponhar o 15 embaixo. Ai eu ponhei do lado.

E-Por que você colocou o um em cima do três?

MI- Porque eu ponhava o 5 aqui (embaixo) dai eu tinha que somar esses dois (parcelas) mais o 1 .
E- Em seguida você fez uma operação de subtração, 56 - 38. Me explique MI- Ei peguei o 6 e o 8 que tirava do 6 , não dava, eu peguei 1 do 5, ficou 4 e no 6 ficou 16. Dai 168 dava 8 e 4 menos 3 dava 1.

E-Você disse que emprestou 1 do 5 , quando você emprestou 1 do 5 para 6 , como você disse. Esse 5 ficou valendo mais ou menos?

MI- Menos.

E- E quanto ficou valendo o 6 . MI- 16.

E-Mas você não emprestou só 1 ? MI- Ham ham.

E-Mas 1 mais 6 não é 7?

$M I-E$.

E- Então como ficou $16 ?$

MI- ( a criança não responde)

TESTE 3 ( KAMII, 1992, p. 42)

Descrição: Às crianças foram entregues cartões do tipo:

\begin{tabular}{|c|c|c|c|c|c|}
\hline 1 midade & 2 midades & 3 unidades & 4 midades & S midades & 2 certenas \\
\hline 10 mridades & 11 mridades & 12 uridades & 1 dezera & 2 dezenas & 3 certenas \\
\hline 3 dezenas & 40 deremas & 45 dezenas & 51 dezemas & 1 centeng & 5 centernas \\
\hline
\end{tabular}

\begin{tabular}{|lcc|}
\hline 402 & $?$ & 513 \\
& seu rúm ero & \\
&
\end{tabular}


O entrevistador escrevia e lia para elas os numerais 402 e 513, e apresentava uma ficha como o modelo:

Em seguida, dizia ter pensado num número entre 402 e 513, que deveria ser adivinhado pelas crianças. O número deveria ser representado através de cartões, escolhidos dentre os apresentados. Os desempenhos das crianças foram correlacionados com os apresentados no teste 1 .

DA, conforme já identificada, não apresenta desequilíbrio nem a favor da acomodação, nem a favor da assimilação. Quando ela se depara com os cartões, apresenta argumentos que foram retirados de um patamar e transferidos para outro. A ação mental (revelada por suas ações, operações, etc) retira os caracteres essenciais e os utiliza para outras finalidades ( argumenta sobre os procedimentos adotados na manipulação do algoritmo e sobre o porquê da escolha dos cartões). No teste dos cartões, procede da seguinte maneira:

E- Qual foi o número que você escolheu?

DA- 499

E- E quais foram os cartões que você escolheu?

DA- 40 dezenas, 5 dezenas, 4 dezenas, 4 unidades e 5 unidades.

E- E por que?

DA- 40 dezenas é 400, 4 dezenas e 5 dezenas dá 9 dezenas que é 90 e 5 unidades e 4 unidades dá nove mesmo
São novas situações e novos problemas que a criança reconstrói, colocando em relação os elementos extraídos do patamar A.

Sendo a ação mental o elemento constitutivo da organização cognitiva do sujeito, podemos identificar, no plano epistemológico, as relações entre DA e o objeto de conhecimento, a partir da forma como ela se organiza para responder aos desafios do ato cognoscitivo. DA segue argumentando convictamente em todas as demais situações que lhe são propostas.

Vejamos como MI procedeu: 


\begin{tabular}{|c|c|}
\hline 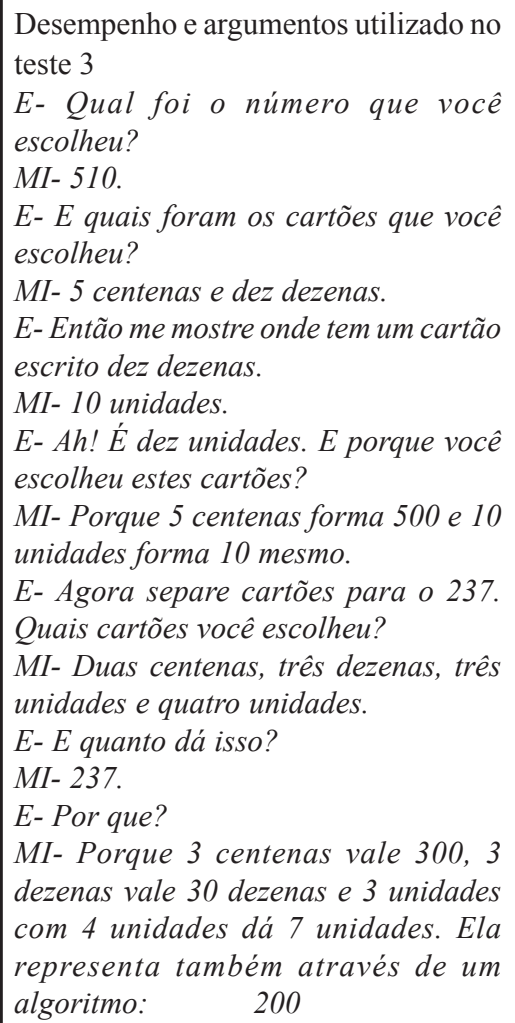 & $\begin{array}{l}\text { E-Tem } 200 \text { centenas aí? } \\
\text { MI- Mas eu coloquei no papel. EUA } \\
\text { peguei } 200 \text { centenas. } \\
\text { E-Mas não tem } 200 \text { centenas. } \\
\text { MI- } 20 \text { centenas. } \\
\text { E- Mas não tem } 20 \text { centenas, tem } 2 \\
\text { centenas. } \\
\text { MI- } 3 \text { dezenas (vale quanto?) vale } 30 \text {, } \\
\text { mais duas centenas e fiz três dezenas } \\
\text { então o sete não tem então eu coloco o } \\
\text { cinco, porque não tem seis nem sete. } \\
\text { E- Mas não tem cartões que somados } \\
\text { dão sete? } \\
\text { MI-Tem } \\
\text { E-E para o } 363 \text { como é que você fez? } \\
\text { MI- Eu coloquei } 3 \text { centenas, mais } 6 \\
\text { dezenas e como não tem } 6 \text { aqui eu } \\
\text { coloquei } 3 \text { unidades. } \\
\text { E- Mas tá faltando sessenta. } \\
\text { MI- Não tem. } \\
\text { E- Mas tem outros cartões que dão } \\
\text { sessenta. } \\
\text { MI- (A criança não consegue locali- } \\
\text { zar) }\end{array}$ \\
\hline
\end{tabular}

MI não consegue localizar corretamente os cartões por contar unitariamente, apesar de identificar as 200 unidades (que ela pensa serem denominadas 200 centenas) e as 30 unidades (que ela pensa serem denominadas 30 dezenas). O mesmo acontece para o 363 onde ela não identifica os cartões de 5 dezenas, 2 dezenas e 10 unidades como representativos do 60. Ela procurou cartões de 60 dezenas ou cartões de 30 dezenas, 20 dezenas e 10 dezenas. Não os tendo encontrado, não os selecionou.
No momento da análise do seu desempenho no teste 1 , não havíamos atribuído importância ao fato de a criança chamar de 10 dezenas as 10 unidades representativas do dígito 1 do 16. Só fomos perceber e considerar significativo tal fato quando não sabíamos explicar o porquê da escolha dos cartões e as dúvidas apresentadas. Só então pudemos correlacionar os desempenhos e entender o estágio em que a criança se encontra: construindo os agrupamentos para a representação de quantidades. 
No caso de FE, conforme apontamos anteriormente, os dígitos da representação estão associados à posição ordinal dos objetos na coleção. Porém, no caso dos algoritmos a criança procede corretamente, não sabendo porém porque procede daquela forma. Não procede corretamente nos cartões, escolhendo o cartão de 5 dezenas e 7 unidades para representar o número escolhido, que foi 507. Vejamos seus argumentos para essa escolha:

\section{E- Quanto vale 5 dezenas?}

FE- 50 e 7 unidades dá 7.

E- E quanto dá 50 mais 7 ?

FE- 57.

E- Qual foi o número que você escolheu?

FE- 507.

E- E como é que fica?

FE-Porque eu coloquei cinco dezenas

e se eu colocasse mais o zero, eu não

ia colocar centenas, porque o zero não

vale e mais sete unidades. Eu fiz a conta

e então deu 507.

E- Então 5 dezenas valem 500?

FE- Não.

E- Então porque você pôs 500?

FE- Não, 500 é o cinco.

Dezenas, unidades, agrupamentos e lei que rege o S.N.D. não são objetos conhecidos por FE. Por isso argumenta não ter escolhido cartões para o zero do 507, pois zero não vale nada. O zero não tem, pois, significado na representação. 5 dezenas e 7 unidades são identificados como 50 e 7 e, portanto, suficientes para representar o 507. O zero do 50 passa a representar o zero do 507.

TESTE 6 (KAMII, 1992, p.49)

Descrição: O entrevistador entrega mais ou menos 200 fichas às crianças. Em seguida, pede que elas contem e escrevam a quantidade através de um numeral. Em seguida, retira um punhado e solicita que as fichas sejam contadas novamente, formando grupos de 10 em 10. Após pede, que as crianças apresentem por escrito o total de fichas restantes e que digam qual foi a quantidade retirada pelo entrevistador.

Objetivos:

- verificar como a criança conta fichas;

- observar como a criança conta de dez em dez;

- verificar como o sujeito estabelece relações entre parte e todo;

- avaliar a capacidade do sujeito de conservar o todo;

- investigar a capacidade do sujeito de avaliar simultaneamente os montes feitos e as fichas dos montes;

- avaliar a capacidade do sujeito de separar o todo em partes e conservar o todo.

O comportamento por imitação não permite que um conhecimento, que foi transmitido e não construído, seja elevado para um novo patamar. Numa outra situação em que fichas são contadas e retiradas, FRA não lança mão do algoritmo que manipula tão 
eficientemente para dar resposta à situação problema que lhe é colocada.

E-Lembra que você contou os feijões e deu 145. Como você fez para contar?

FRA-Eu contei de 10 em 10.

E- Contou de 10 em 10 da primeira vez ou da segunda?

FRA-Primeira.

E-Só podia contar de 10 em 10 ou poderia ser de outro jeito?

FRA-De 20 em 20, de trinta ou quarenta.

E-Por que você contou de $10 \mathrm{em} 10$ ?

FRA-Eu contei de dez em dez porque eu gostei e vai muito mais rápido e a gente não cança (a criança escreve assim) e também é mais gostoso de contar de dez em dez.

E-Então tá bom! Daí eu retirei e você disse que sobrou 5. Só 5. Então você não contou os montinhos de 10 ?

FRA-Contei.

E- E você não sabe quantos montinhos ficaram?

FRA- Não.
No teste com as duzentas fichas, FRA procede da seguinte forma:

E- Então conte de novo. (Ela não conta de 10 em 10 e sim de 1 em 1). Agora eu retirei uma quantidade e você vai contar de 10 em 10 prá me dizer quantos sobraram. (A quantidade inicial dela no copinho foi de 256). Quanto sobrou então?

FRA- 3

E - Não, eu quero saber tudo. Quanto? FRA- 143

E-Agora você tem que me dizer: se você tinha antes 256 e agora tem 143, quantos eu tirei? Você tem condições de saber?

FRA- Não

E-Mesmo olhando estes números 256 e 145?

FRA- Não

E- E se eu tivesse dado aquilo que eu tirei na tua mão, teria jeito de saber quanto foi tirado?

FRA- Teria.

E- Como?

FRA-Contando.
Aqui fica evidente que, mesmo manipulando o algoritmo, FRA não o identifica como ferramenta para dar conta da questão que lhe foi proposta.

Segundo NUNES'\& BRYANT (1997, p. 31),

Uma das dificuldades de usar técnicas matemáticas como ferramentas de pensamento parte da relação entre o domínio de procedimentos gerais e seu uso em situações específicas. Dominar um procedimento geral freqüen- temente não nos diz quando o procedimento é uma boa escolha para resolver um problema. Temos que entender a situação problema a fim de pensar matematicamente sobre ela. [...] é a conexão entre as invariáveis na situação problema e as na ferramenta matemática que define se ela será uma boa ferramenta para a situação. [...] Podemos aprender procedimentos sem entendêlos, mas esta aprendizagem é bastante irrelevante para o nosso 
pensamento. Podemos apenas pensar matematicamente em conceitos que significam algo para nós. Se os sistemas de representação vão influenciar o nosso pensamento, eles devem ter sentidoou seja, eles devem estar conectados com as situações nas quais podem ser usados.

Como para FRA a contagem é a ferramenta de pensamento já assimilada, é esta a ser resgatada para dar conta da situação problema. Por essa razão, ao apresentar dois números, cuja diferença deveria ser obtida com utilização do algoritmo, como sugestão do pesquisador, não fez o menor sentido para fornecer pistas de como saber a quantidade que havia sido retirada. Quando o entrevistador propõe a situação, oferecendo-lhe a oportunidade de ter os objetos retirados à mão, a ferramenta de pensamento relacionada à contagem foi imediatamente pinçada para dar conta de responder à questão. É neste sentido que a abstração reflexionante pode explicar tal procedimento: o sujeito lança mão de um conhecimento construído num patamar A e transfere-o para um patamar B, no qual uma nova situação o exige. Faz isso espontaneamente.

\section{Conclusões}

Os desempenhos apresentados nos diversos testes propostos foram identificados como corretos ou incorretos, dependendo do tipo de teste. Porém, o que o grupo está concluindo é que mesmo quando corretas, as respostas dadas podem não significar compreensão por parte das crianças e sim um comportamento de imitação. Alguns testes propostos permitiram identificar as incompreensões em relação ao objeto matemático. Essa identificação só foi possível em virtude de que as análises se concentraram nos argumentos dados pelas crianças e pela proposta de situações problemas não familiares às crianças. Nas situações familiares, a identificação da incompreensão foi relacionada ao comportamento por imitação.

Segundo BECKER (1993),

[...] o processo de abstração reflexionante comporta sempre dois aspectos inseparáveis: de um lado o reflexionamento e de outro uma reflexão.

Mas de onde vem esse material retirado por reflexionamento? Vem de duas fontes possiveis: a) dos observáveis, isto é, dos objetos ou das ações do sujeito em suas características materiais. $O$ mecanismo que assim procede leva o nome de abstração 'empírica'; b) dos não-observáveis, isto é, das coordenações das ações do sujeito, coordenações endógenas [...]. (p.43)

Quando o sujeito modifica o objeto através da coordenação de suas ações com alguns erros, mas essa modificação não é uma propriedade 
inerente ao objeto, isto é, não está no objeto mas nas relações entre os objetos, temos uma abstração pseudoempírica. Nesse sentido, podemos identificar algumas crianças tentando atribuir significados aos dígitos da representação. Tais propriedades não estão nos objetos, mas lhe são atribuídas pelos sujeitos a partir das relações feitas entre outros objetos, no caso, nomes dos números, nomes dados aos algarismos de acordo com a posição que ocupam na representação. Como esse objeto está em construção, algumas vezes as relações são feitas exitosamente e em outras vezes, não. Faltam elementos para que as relações se completem e configurem um processo de abstração reflexionante, que permitirá a utilização do objeto matemático como ferramenta de pensamento. A abstração significará que o sujeito está retirando, arrancando ou extraindo algo de algo. O sujeito só pode, porém, retirar o que seu esquema de assimilação atual possibilita, disponibiliza no momento.

$\mathrm{O}$ ambiente escolar não pode desconsiderar as contribuições da psicologia se pretende ser identificado como um ambiente de ensino-aprendizagem. Por outro lado, não se pede avançar no programa escolar sem verificar se as crianças possuem os esquemas disponíveis para a assimilação de certos objetos matemáticos.

O grupo conclui, portanto, que é possível, no ambiente escolar, apresentar propostas que investiguem se as crianças possuem os esquemas de assimilação necessários para o enfrentamento de uma nova relação entre sujeito e objeto de conhecimento. Considerando que o sujeito pode modificar um esquema em que as experiências anteriores não permitiram um esquema de assimilação ainda disponível, começamos a ter clareza que o ambiente escolar pode ser rico em desafios e propostas de atividades que permitam ao sujeito rever esquemas anteriores e modificá-los por coordenação de suas próprias ações. Isso será possível se tais propostas permitirem ao sujeito, ao verificar que seus esquemas não são suficientes para dar conta dos desafios, voltar-se para si mesmo para produzir as transformações necessárias. Portanto, as propostas para os alunos não devem ficar em nível do "é assim que se faz". Elas devem permitir que o sujeito faça transformações em seus esquemas que não funcionaram a contento. Só que essas transformações não podem ser ensinadas, o que significa que as propostas devem colocar sempre o sujeito frente a desafios cognitivos, de modo que os esquemas possam ser revistos, transformados para que novas assimilações ou abstrações sejam retiradas dos objetos, das ações ou da coordenação das ações.

A pesquisa em foco aponta que os referidos desafios devem contemplar o objeto matemático Valor Posicional presente no S.N.D, uma das invariáveis presentes em tal sistema, ainda não dominadas pela maioria dos sujeitos que compõem a amostra. Em 
relação aos desafios propostos, o sujeito tem a condição de rever constantemente seus esquemas e respondêlos de formas diferentes a partir das novas assimilações.

Essa questão está muito clara para o grupo que participa junto com os pesquisadores das análises das respostas e desempenhos apresentados pelas crianças. A pesquisa intervenção mostra-se eficaz no tocante à formação do professor (e aqui estamos falando também dos pesquisadores que são professores), visto que permite uma relação com o objeto matemático antes não possibilitada pelas ações cotidianas do ambiente da sala de aula. Está permitindo verificar que o ambiente da sala de aula pode ser de investigação da real compreensão dos objetos matemáticos pelos alunos, ao mesmo tempo em que possiblita a construção dos mesmos pelos alunos e pelos professores.

O que se torna necessário é a consideração das contribuições da psicologia, cujos resultados não podem ficar restritos ao seu domínio, uma vez que estamos no ambiente escolar, lidando com questões de aprendizagem que implicam a construção do conhecimento. Como lidar com questões relativas à construção do conhecimento e nos identificarmos como construtivistas, se não entendemos sequer como se dá tal construção? O senso comum, o domínio do conteúdo não constituem instrumentos suficientes para dar conta de tal tarefa. Os encaminhamentos metodológicos e o pro- cesso de avaliação, elementos constituintes do ambiente escolar, mais especificamente da sala de aula, devem considerar o duplo movimento que conduz as assimilações e acomodações a um equilíbrio dinâmico entre as diferenciações e integrações que constituem o processo fundamental, que deve ser compreendido para ser contemplado. Esse movimento exprime as relações complexas de um sujeito que se aproxima de um objeto e de um objeto que recua à medida que as descobertas e propriedades recentemente cognoscíveis levantam novos problemas. Na realidade, devemos considerar que na construção do conhecimento os desequilíbrios dinâmicos, que permitem trocas com o exterior, devem substituir os equilíbrios sem trocas, possibilitados pela transmissão de conhecimentos. Serão as trocas que, pelas suas regulações, estabelecerão as estruturas. A equilibração, por sua vez, é categorizada pela auto-regulação.

A pesquisa, portanto, está possibilitando verificar a eficácia do processo de formação do professor, permitindo identificar que as crianças, apesar do nível avançado de escolaridade, encontram-se em estágios iniciais de construção do campo numérico e de um sistema de representação de quantidades. Está, por conseguinte, esboçando um caminho a ser percorrido para permitir que a assimilação do Valor Posicional seja possibilitada às crianças e para oportunizar a reorganização da prática 
educativa a partir da postura do professor pesquisador, sem a qual as mudanças serão inócuas, consolidando caminhos que vão do nada a lugar nenhum.

\section{REFERÊNCIAS BIBLIOGRÁFICAS}

1 BECKER, Fernando. Ensino e construção do conhecimento: o processo de abstração reflexionante. Educação e Realidade, Porto Alegre, 18 (10), p.43-52, jan/jun, 1993.

2 KAMII, C.; JOSEPH, Linda Leslie. Aritmética: novas perspectivas - implicações da teoria de Piaget. Campinas : Papirus, 1992.

3 NUNES, T.; BRYANT, P. Crianças fazendo matemática. Porto Alegre : Artes Médicas, 1997.

4 PIAGET, JEAN. Abstração reflexionante: relações lógico aritméticas e ordem das relações espaciais. Porto Alegre : Artes Médicas, 1995.

5 PIAGET, Jean; GARCIA, Rolando. Psicogênese e história das ciências. Lisboa : Pub. Dom Quixote, 1987.

6 ROSSO, A.; BECKER, F.; TAGLICHER, J.E. Ação mental: o elemento central da construção do conhecimento. Texto digitado/1999. 